\title{
Preoperative ultrasound localization of the lambda in patients with scaphocephaly: a technical note for minimally invasive craniectomy
}

\author{
Christopher M. Bonfield, MD, D. Douglas Cochrane, MD, Ash Singhal, MD, and \\ Paul Steinbok, MBBS
}

Division of Pediatric Neurosurgery, Department of Surgery, University of British Columbia and BC Children's Hospital, Vancouver, British Columbia, Canada

\begin{abstract}
Sagittal craniosynostosis, the most common single suture craniosynostosis, is treated by numerous surgical techniques. Minimally invasive endoscopy-assisted procedures with postoperative helmeting are being used with reports of good cosmetic outcomes with decreased morbidity, shortened hospital stay, and less blood loss and transfusion. This procedure uses small skin incisions, which must be properly placed to provide safe access to the posterior sagittal and lambdoid sutures. However, the lambda is often hard to palpate through the skin due to the abnormal head shape. The authors describe their experience with the use of intraoperative, preincision ultrasound localization of the lambda in patients with scaphocephaly undergoing a minimally invasive procedure. This simple technique can also be applied to other operations where proper identification of the cranial sutures is necessary.
\end{abstract}

http://thejns.org/doi/abs/10.3171/2015.5.PEDS15157

KEY WORDS craniosynostosis; cranial suture; lambdoid suture; ultrasound; sonography; craniofacial; technique

\footnotetext{
$\mathrm{C}$
} RANIOSYNOSTOSIS, the premature fusion of a cranial suture, occurs in approximately 1 of 2500 live births. The most common suture affected is the sagittal suture, representing more than $50 \%$ of nonsyndromic cases. ${ }^{9}$ In this type of synostosis, compensatory skull growth is stereotypically long and narrow, resulting in a scaphocephalic head shape. Traditional open techniques, such as cranial vault remodeling or extended strip craniectomies, have been used to treat the condition. More recently, minimally invasive endoscopy-assisted procedures with postoperative helmeting are being used with reports of good cosmetic outcomes with decreased morbidity, shortened hospital stay, and less blood loss and transfusion. ${ }^{1-3,5,8}$ The surgery is typically performed through 2 small $(2-4 \mathrm{~cm})$ skin incisions, one posterior to the anterior fontanelle and another anterior to the lambda (Fig. 1). ${ }^{2}$ For ease and safety of the operation, it is imperative that these incisions be placed correctly. Due to the scaphocephaly and the often deformed and pointed occipital region, the lambda is often hard to palpate through the skin. The purpose of this report is to describe the use of intraoperative, preincision ultrasound localization of the lambda in patients with scaphocephaly undergoing a minimally invasive procedure.

\section{Technique}

The patient is positioned and secured on the operating table in either a prone sphinx or lateral position. Prior to prepping or draping, a linear array ultrasound probe (MTurbo Ultrasound, SonoSite Inc.) is placed in a transverse (coronal) plane perpendicular to the fused sagittal suture. In the area of fusion, no hypoechoic suture will be seen in the hyperechoic bone. In most cases, a ridge will be seen in this area as well (Fig. 2). As the ultrasound probe is moved posteriorly, a small part of the sagittal suture may be visible as a single hypoechoic line (if the suture is not completely fused) (Fig. 3). The lambda will be recognized where the hypoechoic open suture becomes slightly wider (Fig. 4) and subsequently splits into 2 divergent lambdoid sutures (Fig. 5). With the lambda localized, the posterior skin incision can be marked accurately. The patient can then be prepared and draped, and the operation can commence. A similar technique can also be used for the localization of the coronal suture, although it can usually 


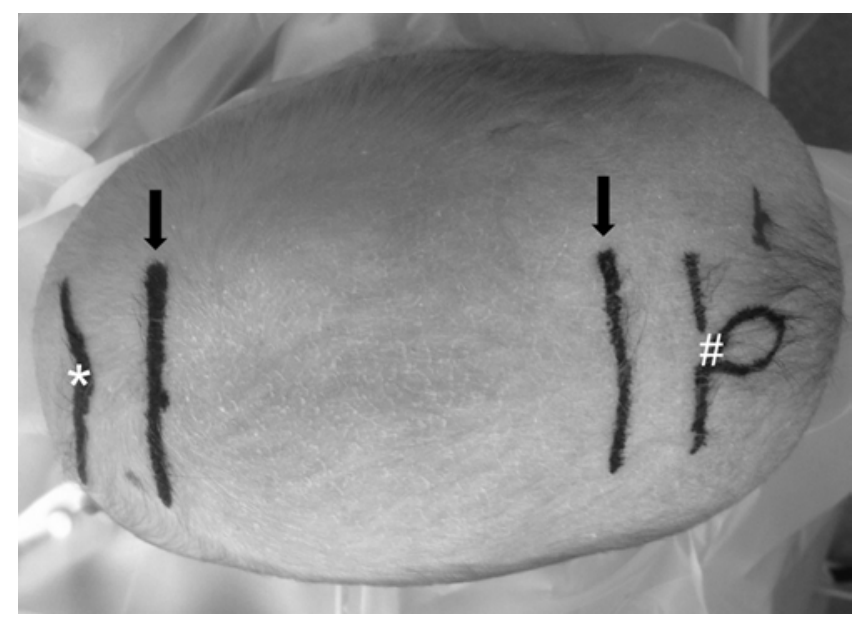

FIG. 1. Incision markings (arrows) before surgical preparation. Note the position in relation to the lambda (asterisk) and anterior fontanelle/coronal sutures (pound sign).

be palpated, especially if an open anterior fontanelle is present.

\section{Results}

At our institution, we have applied this technique to locate the lambda in 5 consecutive children undergoing an endoscopy-assisted craniectomy for sagittal synostosis. In these patients, the attending neurosurgeon, pediatric neurosurgery fellow, and neurosurgery resident all independently marked the lambda according to the ultrasound technique described above. The lambda was consistently and accurately located, regardless of the level of training of the surgeon.

The location of the lambda was confirmed under direct visualization intraoperatively. In each case, the ultrasound-guided skin marking of the lambda accurately corresponded to the actual suture location on the skull as seen during the operation.

\section{Discussion}

In some cases of endoscopy-assisted craniectomies for sagittal synostosis at our institution, the posterior incision has been placed too far anterior when the lambda could not be easily palpated due to the patient's abnormal head shape. This resulted in a more difficult operation, decreased visualization of and access to lambda during the operation, and ultimately led to increasing the size of the

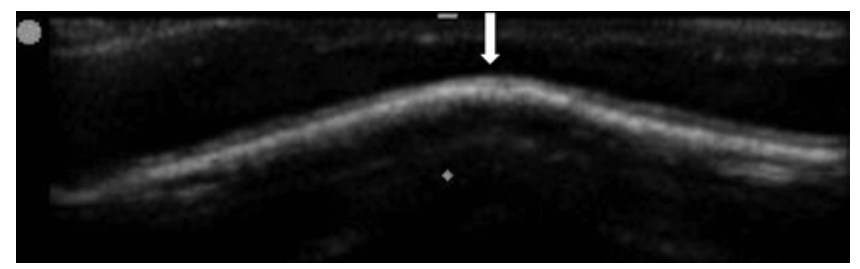

FIG. 2. Ultrasound image of a fused sagittal suture demonstrating hyperechoic bone and ridge (arrow).

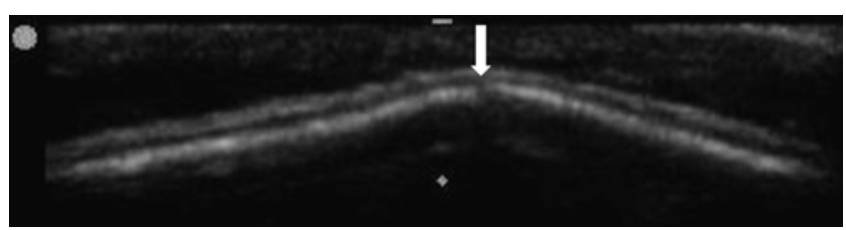

FIG. 3. Ultrasound image of the posterior sagittal suture showing a small area of the patient's hypoechoic suture (arrow).

incisions. A technique allowing more accurate localization of the lambda at the time of surgery could avoid this problem. With that in mind, we thought that ultrasound might be an appropriate tool to achieve this.

Previous investigations had shown the ability of ultrasound to locate cranial sutures independent of patient age. ${ }^{10}$ Some authors advocate for the use of ultrasound as a way of screening for the patency of sutures in cases of plagiocephaly. ${ }^{4,7,11,12}$ Hyperechoic fusion of bones and ridging are characteristic aspects of suture synostosis. ${ }^{6}$ It is with this background that we applied ultrasound to try and identify more precisely the lambda in infants undergoing minimally invasive endoscopy-assisted craniectomies for sagittal synostosis.

Our experience, albeit limited to a few patients so far, indicates that ultrasound in the operating room allows accurate localization of the lambda for operative planning purposes in cases of endoscopy-assisted craniectomies for sagittal synostosis. This technique is fast, inexpensive, noninvasive, radiation-free, and easy to perform and interpret. We have also demonstrated that this technique can be easily learned and used by attending, fellow, and resident neurosurgeons with good accuracy and reproducibility. Furthermore, ultrasound localization of the sutures can be done with any portable ultrasound machine and numerous probes (linear and curved array), including those used for intravenous catheter placement. It is for these reasons that we now routinely use ultrasound as a tool to plan our posterior incision these cases.

The use of preoperative ultrasound can also be extended beyond its application in sagittal synostosis. Coronal synostosis is being treated in a similar fashion with minimally invasive techniques. We have also used ultrasound to locate the squamosal suture in 1 case of endoscopy-assisted craniectomy for unicoronal synostosis. This suture, which marks the inferior extent of the craniectomy, cannot always be palpated and is often hard to visualize intraoperatively. Furthermore, ultrasound can be used to locate the coronal suture for accurate starting placement of a ventricular drain or ventriculoperitoneal shunt to avoid the

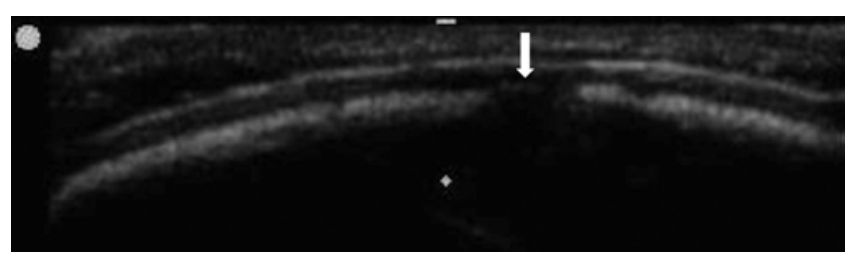

FIG. 4. Ultrasound image of the anterior part of the lambda, revealing a wider hypoechoic area (arrow). 


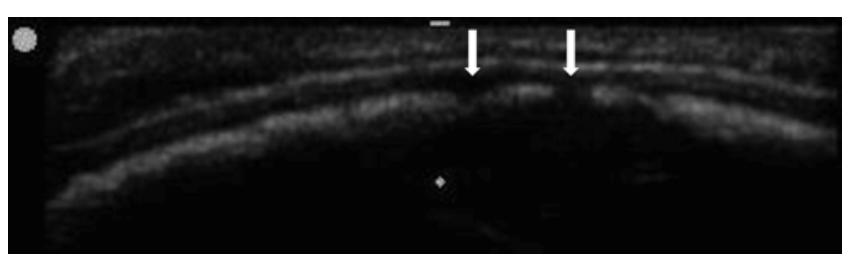

FIG. 5. Ultrasound image of the beginning of divergent lambdoid sutures (arrows).

more eloquent parts of the cortex posteriorly, especially in children without full-grown skulls and consistent measurements.

\section{Conclusions}

In cases of minimally invasive endoscopy-assisted craniectomies for sagittal synostosis, where accurate placement of incisions is important and posterior landmarks cannot be palpated, utilizing ultrasound prior to skin incision is a simple and reliable method to locate the lambda prior to making an incision. This simple technique can also be applied to other operations where accurate identification of the cranial sutures is necessary.

\section{Acknowledgment}

Dr. Bonfield is supported by the Jonathan Lawson Neurosurgery Fellowship Fund.

\section{References}

1. Gociman B, Marengo J, Ying J, Kestle JR, Siddiqi F: Minimally invasive strip craniectomy for sagittal synostosis. J Craniofac Surg 23:825-828, 2012

2. Jimenez DF, Barone CM: Endoscopic technique for sagittal synostosis. Childs Nerv Syst 28:1333-1339, 2012

3. Jimenez DF, Barone CM, McGee ME, Cartwright CC, Baker CL: Endoscopy-assisted wide-vertex craniectomy, barrel stave osteotomies, and postoperative helmet molding therapy in the management of sagittal suture craniosynostosis. J Neurosurg 100 (5 Suppl Pediatrics):407-417, 2004

4. Krimmel M, Will B, Wolff M, Kluba S, Haas-Lude K, Schaefer J, et al: Value of high-resolution ultrasound in the differential diagnosis of scaphocephaly and occipital plagiocephaly. Int J Oral Maxillofac Surg 41:797-800, 2012
5. Meier PM, Goobie SM, DiNardo JA, Proctor MR, Zurakowski D, Soriano SG: Endoscopic strip craniectomy in early infancy: the initial five years of anesthesia experience. Anesth Analg 112:407-414, 2011

6. Regelsberger J, Delling G, Helmke K, Tsokos M, Kammler $\mathrm{G}$, Kränzlein H, et al: Ultrasound in the diagnosis of craniosynostosis. J Craniofac Surg 17:623-628, 2006

7. Regelsberger J, Delling G, Tsokos M, Helmke K, Kammler $\mathrm{G}$, Kränzlein H, et al: High-frequency ultrasound confirmation of positional plagiocephaly. J Neurosurg 105 (5 Suppl):413-417, 2006

8. Shah MN, Kane AA, Petersen JD, Woo AS, Naidoo SD, Smyth MD: Endoscopically assisted versus open repair of sagittal craniosynostosis: the St. Louis Children's Hospital experience. J Neurosurg Pediatr 8:165-170, 2011

9. Slater BJ, Lenton KA, Kwan MD, Gupta DM, Wan DC, Longaker MT: Cranial sutures: a brief review. Plast Reconstr Surg 121:170e-178e, 2008

10. Soboleski D, McCloskey D, Mussari B, Sauerbrei E, Clarke M, Fletcher A: Sonography of normal cranial sutures. AJR Am J Roentgenol 168:819-821, 1997

11. Soboleski D, Mussari B, McCloskey D, Sauerbrei E, Espinosa F, Fletcher A: High-resolution sonography of the abnormal cranial suture. Pediatr Radiol 28:79-82, 1998

12. Sze RW, Parisi MT, Sidhu M, Paladin AM, Ngo AV, Seidel $\mathrm{KD}$, et al: Ultrasound screening of the lambdoid suture in the child with posterior plagiocephaly. Pediatr Radiol 33:630636,2003

\section{Disclosure}

The authors report no conflict of interest concerning the materials or methods used in this study or the findings specified in this paper.

\section{Author Contributions}

Conception and design: all authors. Acquisition of data: Bonfield. Analysis and interpretation of data: Bonfield, Cochrane, Singhal. Drafting the article: Bonfield, Cochrane. Critically revising the article: all authors. Reviewed submitted version of manuscript: all authors. Approved the final version of the manuscript on behalf of all authors: Bonfield. Study supervision: Steinbok.

\section{Correspondence}

Christopher M. Bonfield, Division of Pediatric Neurosurgery, Department of Surgery, University of British Columbia and BC Children's Hospital, 4480 Oak St., Vancouver, BC V6H 3V4, Canada. email: bonfieldem@gmail.com. 